\title{
ACROSPIROMA OF BREAST: A RARE CLINICALLY SIGNIFICANT DIFFERENTIAL DIAGNOSIS IN BREAST LUMP - A CASE REPORT
}

Shalini Kashyap ${ }^{1}$, Kamal Jyoti ${ }^{2}$

\section{HOW TO CITE THIS ARTICLE:}

Shalini Kashyap, Kamal Jyoti. "Acrospiroma of Breast: A Rare Clinically Significant differential Diagnosis in Breast Lump - A Case Report". Journal of Evolution of Medical and Dental Sciences 2015; Vol. 4, Issue 72, September 07; Page: 12614-12617, DOI: $10.14260 /$ jemds/2015/1817

ABSTRACT: Acrospiroma or nodular hidradenoma is an uncommon skin adnexal tumor arising from eccrine glands. Acrospiroma of the breast is a rare entity. Failure to identify its cytomorphologic features and rarity of this tumor may lead to misdiagnosis. Hereby we report a case of 23 year-old female who presented with painless lump in left breast since 4 months. Fine needle aspiration cytology of lump suggested possibility of atypical breast lesion and patient was advised a biopsy examination. Final diagnosis of acrospiroma was made on histopathologic examination. It is mandatory amongst pathologists to have awareness of cytomorphologic features of breast acrospiroma and also amongst surgeons to keep it as possible clinical diagnosis, for correct management of the patients and for avoiding unwarranted mastectomy.

KEYWORDS: Acrospiroma, Breast lump, Rare, Skin adnexal tumor.

INTRODUCTION: Acrospiroma is an uncommon adnexal tumor arising from eccrine glands and commonly seen on the face and the upper extremities. It is a rare lesion amongst the skin adnexal tumor known to arise from the breast and to best of our knowledge only few cases have been reported in the literature.(1) Rarely benign acrospiroma can transform into malignant form; malignant transformation observed in only $5 \%$ of the cases. It usually occurs in the nipple and subareolar region of the breast and is one of the differential diagnoses for subareolar breast tumors. It can also occur deep within the breast tissue. (2) Being rare in the breast, these lesions on fine needle aspiration cytology which is a common modality for breast lump are either inconclusive or misdiagnosed.(2) They are usually reported only after histopathological examination. Adequate excision with wide margins is the usual line of treatment for acrospiroma of breast.

CASE REPORT: A 23 years-old female presented with painless lump near areolar region of left breast since 4 months. There was no history of pain, trauma, fever, nipple discharge or retraction. Family history was negative. Menstrual and obstetric history also not significant. On local examination, skin near the area of incision line was mildly indurated. No lymphadenopathy present. Fine needle aspiration cytology (FNAC) was already performed from an outside laboratory where cytological diagnosis of atypical breast lesion was made and patient was advised lumpectomy. Excision biopsy was performed and mass was sent for histopathological examination. Histological diagnosis of acrospiroma was made. Postoperative course was uneventful. Contact with patient was lost after 2 months.

PATHOLOGICAL FINDINGS: Grossly, the excised mass was partially soft and measured $4.5 \mathrm{~cm} \times 3.0 \mathrm{~cm}$ in size. Cut section revealed a cystic lesion with solid component measuring $2.5 \mathrm{~cm} \times 1.5 \mathrm{~cm}$ in size. Hematoxylin and Eosin stained sections of paraffin embedded blocks showed tumor comprised of lobules, solid sheets and papillary formations of tumor mass separated by fibroconnective tissue stroma with slit-like spaces (Fig. 1). The tumor cells were of two types; polyhedral cells having 
moderately abundant eosinophilic cytoplasm with round vesicular nucleus; other cells being round having vacuolated to clear cytoplasm with centrally to eccentrically placed round to oval nucleus (Fig. 2). These clear cells showed Periodic Acid Schiff positivity. Tubular lumina were seen; few having eosinophilic material / secretions. Focus of squamoid metaplasia also seen. No marked pleomorphism or necrosis was seen. However, mitoses were frequent. The cyst was lined by cuboidal epithelium. Intervening areas showed eosinophilic hyalinizing stroma. Final diagnosis of acrospiroma was made.

DISCUSSION: Acrospiroma is a benign dermal tumor, which arises from distal excretory ducts of eccrine sweat Glands; also known as clear cell hidradenoma, nodular hidradenoma and solid-cystic hidradenoma. And is seen most often in young adults and appears to be slightly more common in women than in men.(1,2) The most common clinical presentation is slow growing, painless lump in the breast, occasionally associated with pain, nipple discharge or ulceration of the overlying skin.(1,2) Common sites of origin are face, upper extremity, axilla, trunk, thigh, scalp and pubic region. Acrospiroma of breast is very rare and only few cases have been reported in English literature. It shares features with its counterparts elsewhere in the body.(2) In most of the instances it is usually between $0.5 \mathrm{~cm}$ to $2.0 \mathrm{~cm}$ in size although they can be larger in size. Acrospiroma of breast probably has two distinct histogenetic origin; from skin adnexal glands and from mammaryducts.(3) According to the literature 47 percantage of acrospiroma of breast originated from the nipple or areola whereas 53 percentage originated from deep mammary glands like in our case.

Malignant transformation of acrospiroma is extremely rare with very few well documented cases are reported in literature.(4) Eccrine carcinoma equally affects both sexes in the sixth and seventh decade. Latest updates show that, as compared to benign counterpart some eccrine carcinoma are positive to estrogen and progesterone receptors which has an important clinical implication.(4)

Usually, acrospiroma is difficult to diagnose cytologically and in most studies, cytological diagnosis was either inconclusive or misdiagnosed as breast cancer. Histopathological examination usually confirms the diagnosis. Histology shows lobulated tumor masses located in dermis resembling eccrine poroma with two cell types. Tubular lumina of various sizes and often cystic spaces due to degeneration of tumor cells are seen.(4,5) Acrospiroma does not show marked pleomorphism and frequent mitoses; if such changes are present, the tumor should be considered to have a potential for aggressive behaviour. Necrosis, infilterative, poorly circumscribed and asymmetrical perimeter are indicators of malignancy.(5) In some tumors squamoid differentiation is also seen like in our case.(5,6) Histopathologically it needs to be differentiated from primary breast carcinoma, metastatic renal carcinoma and other skin adnexal tumors with follicular differentiation, sebaceous differentiation or sweat gland differentiation which are known to arise from breast.(5,6) Immunohistochemistry (IHC) further aids in ruling other differentials. IHC of acrospiroma is characteristically negative for estrogen receptors, progesterone receptors and smooth muscle actin; positive for keratin, EMA, CEA, S-100 with Gross cystic disease fluid (GCDF) being a useful marker to exclude apocrine differentiation but is rarely performed.

Complete surgical excision with safe margins and regular follow-up is the treatment of choice for breast acrospiroma.(6,7) Inadequate excision leads to its recurrence though exact incidence is not reported by authors. ${ }^{(7)}$ Therefore, acrospiroma should be considered in both sexes in the differential diagnosis of breast neoplasms, especially when the lump is situated in the nipple and areolar region. Awareness amongst surgeons and pathologist for the possibility of diagnosing acrospiroma is mandatory as to avoid unwarranted mastectomy. 


\section{CASE REPORT}

\section{REFERENCES:}

1. Ohi Y, Umekita Y, Rai Y, et al. Acrospiroma of the breast: a case report with review of the literature. Breast Cancer 2007; 14: 307-11.

2. Mote DG, Ramamurti T, Babu B. Naveen. Nodular hidradenoma of the breast: A case report with literature review. Indian J Surg 2009; 71: 43-5.

3. Domoto H, Terahata S, Soto K, Tamai S. Nodular hidradenoma of the breast: report of two cases with literature review. Pathol Int 1998; 48: 907-11.

4. Christopher Hale. Latest Updates. Skin - Non melanocytic tumors. Adnexal tumors -Sweat gland derived Hidradenoma/eccrine poroma. Pathology Outlines.com, Inc. 2003-2015.

5. Ahmed TS, Priore JD, Seykora JT. Tumors of the epidermal appendages. In: Elder DE, Elenitsas R, Murphy GF, Johnson BL, Xu X, editors. Lever's histopathology of the skin, $10^{\text {th }}$ edition. Philadelphia: Lippincott Williams and Wilkins; 2009. p. 891-2.

6. Kajal Kiran Dhingra, Shramana Mandal, Nita Khurana. An unuasual case of nodular hidradenoma of breast. Iranian Journal of Pathology 2007; 2:80 - 82.

7. Girish G, Gopashetty M, Stewart R. Reccurent clear cell hidradenoma of the breast: a case report. The Internet J Surgery 2007; 10:1-5.

Fig. 1: Section showing nests, lobules and solid sheets of tumor mass separated by fibroconnective tissue stroma. (Hematoxylin and Eosin X 100).

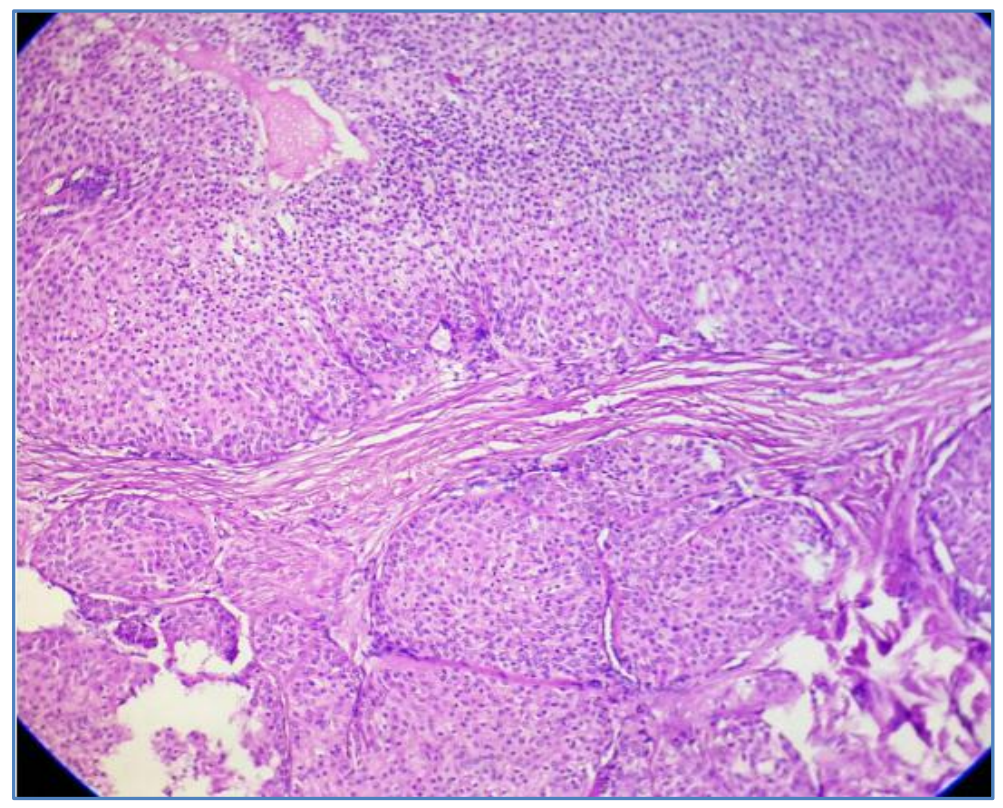

\section{Fig. 1}




\section{CASE REPORT}

Fig. 2: Section showing two types of tumor cells one with clear cytoplasm; other having abundant eosinophilic cytoplasm along with area showing squamoid differentiation. (Hematoxylin and Eosin X 100).

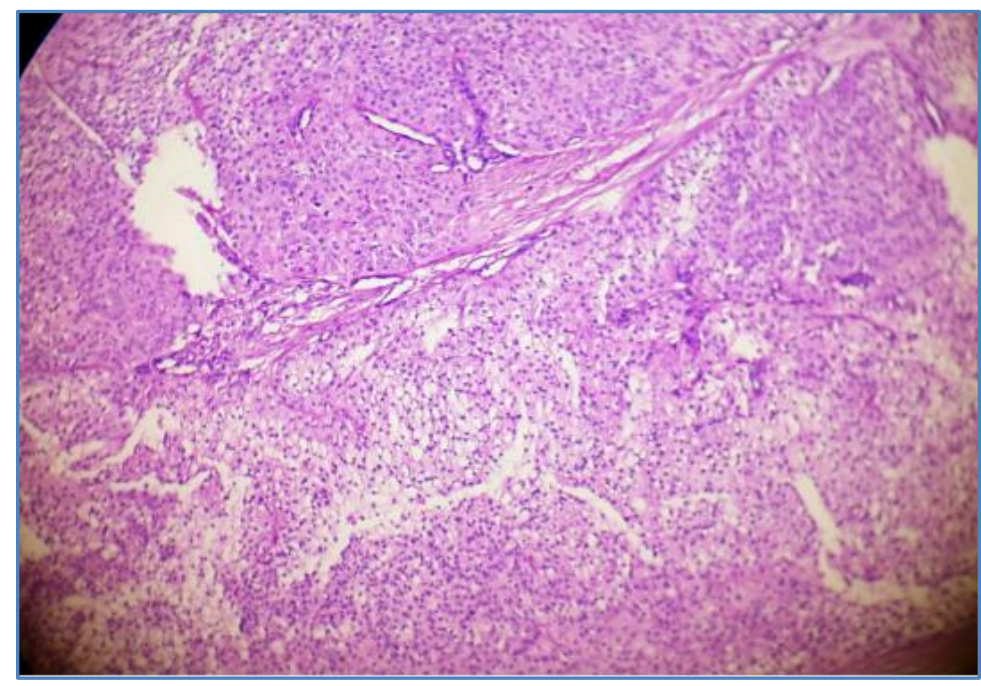

\section{Fig. 2}

\section{AUTHORS:}

1. Shalini Kashyap

2. Kamal Jyoti

\section{PARTICULARS OF CONTRIBUTORS:}

1. Associate Professor, Department of Pathology, Chintpurni Medical College \& Hospital, Dalhousie Road, Pathankot, Punjab.

2. Medical Officer, Department of Anaesthesia, Govt. Medical College, Amritsar, Punjab.

NAME ADDRESS EMAIL ID OF THE CORRESPONDING AUTHOR:

Dr. Shalini Kashyap,

B/566, Ranjit Avenue, Amritsar, Punjab.

E-mail: gauryanheerak@gmail.com

Date of Submission: 20/08/2015.

Date of Peer Review: 21/08/2015.

Date of Acceptance: 02/09/2015.

Date of Publishing: 07/09/2015. 